
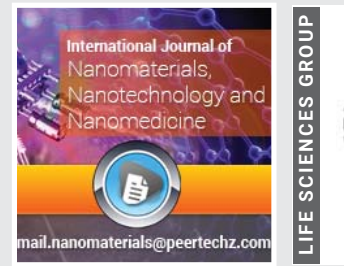

\section{Ultrasound assisted}

\section{synthesis of nanosized oxide semiconductors/}

\section{ordered mesoporous carbon}

\section{nanoarchitectures}

\author{
Maria Ignat ${ }^{1,2 \star}$, Liviu Sacarescu ${ }^{2}$ and Aurelia Vasile ${ }^{1}$ \\ 1Department of Chemistry, "Alexandru loan Cuza" University of lasi, 11 Carol I Bvd, 700506, lasi, \\ Romania \\ ${ }^{2}$ Institute of Macromolecular Chemistry “Petru Poni”, 41A, Gr. Ghica Voda Alley, 700487, Iasi, Romania
}

Received: 10 January, 2019

Accepted: 31 January, 2020

Published: 03 February, 2020

*Corresponding author: Maria Ignat, Materials Chemistry Laboratory, Department of Chemistry, "Alexandru Ioan Cuza" University of Iasi, 11 Carol I Bvd, 700506, Iasi, Romania, Tel: +40 232 201314; Fax: +40 232 201313; E-mail: maria.ignat@uaic.ro

https://www.peertechz.com

Check for updates

\title{
Abstract
}

The present work reports the ultrasound assisted synthesis of nanosized oxide semiconductors, as $\mathrm{TiO}_{2}\left(\right.$ anatase) and $\mathrm{Bi}_{2} \mathrm{O}_{3}(\mathrm{a}-\mathrm{phase}) / \mathrm{mesoporous} \mathrm{carbon} \mathrm{stable}$ architectures exhibiting high photocatalytic activity for organic pollutants degradation.

The use of ordered mesoporous carbon with a pore diameter around $5 \mathrm{~nm}$ and high specific surface area of $1392 \mathrm{~m}^{2} / \mathrm{g}$ was a successful one, providing an ideal support for semiconductor oxide photocatalysts. Thus, by using ultrasound assisted method the photoactive systems for organics removal from waste waters has been obtained.

Due to the presence of the polar oxygenated groups on mesoporous carbon surface, these might stimulate the formation of the stable (nano) architectures, and enhance the interfacial combination of semiconducting oxide nanoparticles with carbon nanostructure. The prepared systems by this way have been characterized by $\mathrm{N}_{2}-$ sorption measurements, X-ray diffraction, SEM microscopy and FTIR spectroscopy. A correlation between their structural, textural and morphological properties is related, and the photocatalytic activity of the synthesized materials has been checked for the methyl orange bleaching in liquid phase, under UV light.

The photocatalytic performance of the synthesized nanosized oxide semiconductors/ordered mesoporous carbon nanoarchitectures was evaluated by bleacing of Methyl Orange (MO). It was found that the synthesized $\mathrm{a}-\mathrm{Bi}_{2} \mathrm{O}_{3} /$ mesoporous carbon and $\mathrm{TiO}_{2} /$ mesoporous carbon composites showed a much higher degradation efficiencies (of $95 \%$ and $98 \%$, respectively) as compared to commercial anatase nanoparticles. For the enhanced photocatalytic activity of the composite systems is responsible the synergistic effect as result of mesoporous carbon structure - oxide semiconductor interactions.

\section{Introduction}

In recent years, the application of high intensity ultrasound to the synthesis of nanostructured materials has attracted much attention [1]. Providing control over the size, morphology and nano/microstructure of metal oxides, the main advantages of the sonochemical approach evaluated against conventional methods are the time-shortening of the sol-gel reaction, the size distribution uniformity and improved phase purity, recognized also by many other research groups.

Due to their physical and chemical properties, ordered mesoporous carbons are considered interesting materials that can be used in a wide field of applications like adsorption, catalysis, water and air purification or energy storage [2]. They are inert and have attracted broad interest due to welldefined structure, appropriately pore size, large pore volume and high specific surface area, as well as a high mechanical stability. Earlier, activated carbon has been used as supporting material to enhance the photocatalytic activity of anatase [3]. But, its irregular pore structure led to a decreased adsorption of organics influencing the performance of the photocatalyst. In order to solve this problem, ordered mesoporous carbons 
are synthesized [4] and used as support, thus increasing the photocatalytic efficiency of $\mathrm{TiO}_{2}$-based photocatalysts [5]

The main objective of this study was to prepare oxide semiconductor nanoparticles using the ultrasound-assisted synthesis, immobilizing them on ordered mesoporous carbon structures and use the obtained composites for the removal of dyes from polluted water. Due to their electronic structure, oxide semiconductors (e.g., $\mathrm{TiO}_{2}, \mathrm{ZnO}, \mathrm{Bi}_{2} \mathrm{O}_{3}, \mathrm{SnO}_{2}, \mathrm{~V}_{2} \mathrm{O}_{5}, \mathrm{Fe}_{2} \mathrm{O}_{3}$ ) act as sensitizers for light-reduced red-ox processes [6]. Although, $\mathrm{TiO}_{2}$ is the most studied photocatalyst for the last two decades due to its photocatalytic properties, nontoxicity and stability, bismuth oxide, $\mathrm{Bi}_{2} \mathrm{O}_{3}$, has attracted a great attention due to its variable band gap energy (from 2 to $3.96 \mathrm{eV}$ ), being excited by the light ranging from visible to ultraviolet [7].

As the efficiency of oxide semiconductor is limited by the electron-hole recombination process, by supporting nanoparticles on carbon materials, the charge separation could be stabilized, as well as the charge recombination could be reduced, thus enhancing the photocatalyst reactivity. Therefore, oxide semiconductor nanoparticles supported on ordered mesoporous carbon could show an increased photoresponse, due to the carbon structures that are able to promote a rapid photoinduced charge separation and slow charge recombination, by accepting the photogenerated electrons from photocatalytic nanoparticles. Accordingly, this work deals first with the sonochemical-assisted synthesis and characterization of photoactive catalyst comprised of $\mathrm{TiO}_{2}$ (anatase) and $\mathrm{Bi}_{2} \mathrm{O}_{3}$ ( $\alpha$-phase) oxides supported on ordered mesoporous carbon structures, exhibiting high photocatalytic activity. As heterogeneous photocatalysis using oxide semiconductor has demonstrated to be very effective in the oxidation of different organic compounds, the synthesized materials have been tested in dye bleaching process. Accordingly, the target pollutant was methyl orange (MO), as a representative of a commercial anionic class of dyes, being stable to visible and UV lights.

\section{Experimental}

\section{Materials and equipment}

All reagents used in the experiment were of AR grade purchased from Aldrich and Acros Organics: tetraethyl orthosilicate $\left(\mathrm{Si}\left(\mathrm{OC}_{2} \mathrm{H}_{5}\right)_{4}\right)$ and tri-block copolymer poly (ethylene glycol)-block-poly (propylene glycol)-block-poly(ethylene glycol) (Pluronic P123, molecular weight $=5800, \mathrm{EO}_{20} \mathrm{PO}_{70} \mathrm{EO}_{20}$ ), glycerol $\left(\mathrm{C}_{3} \mathrm{H}_{5}(\mathrm{OH})_{3}\right)$, bismuth (III) nitrate pentahydrate $\left(\mathrm{Bi}\left(\mathrm{NO}_{3}\right)_{3} \cdot 5 \mathrm{H}_{2} \mathrm{O}\right)$, titanium (IV) butoxide $\left(\mathrm{Ti}\left(\mathrm{OCH}_{2} \mathrm{CH}_{2} \mathrm{CH}_{2} \mathrm{CH}_{3}\right)_{4}\right)$, isopropyl alcohol $\left(\mathrm{i}-\mathrm{C}_{3} \mathrm{H}_{7} \mathrm{OH}\right)$, nitric acid $\left(\mathrm{HNO}_{3}\right)$. All products were utilized as received. Deionized water used throughout the experiments was prepared with an ELGA purelab water system.

The reaction mixtures have been irradiated with a high intensity ultrasonic generator SONICS VIBRA CellTM Model CV 33 (1.13cm diameter Ti horn) with $750 \mathrm{~W}$ power and working frequency of $20 \mathrm{kHz}$, pulsed mode (3s/1s on/off cycle). The temperature during the sonication increased up to $60^{\circ} \mathrm{C}$.

Powder X-ray diffraction patterns (PXRD) were recorded using a Bruker D8 Advance AXS diffractometer, Bragg-
Brentano parafocusing goniometer, with Soller and fixed slits, using a Ni-filtered $\mathrm{Cu} \mathrm{K} \alpha$ radiation $(\lambda=0.1541 \mathrm{~nm})$, with an emission current of $25 \mathrm{~mA}$ and a voltage of $36 \mathrm{kV}$. Scans were collected at room temperature, over the scattering angle $(2 \theta)=20-60^{\circ}$ range, using a step size of $0.02^{\circ}$. As well, for the structural investigation of the mesoporous systems, smallangle X-ray scattering measurements (SAXS) on the powdered samples were carried out. The analysis has been performed on a Bruker-Nanostar $\mathrm{U}$ apparatus equipped with a 3-pinhole collimation system that provides a precisely parallel X-ray beam with high intensity and virtually no background, so that fast measuring times and extremely high resolution can be achieved.

BET-specific surface area of starting material and resulted composites were calculated from nitrogen adsorption isotherm determined at 77K using a Quantachrome Nova 2200 Instrument \& Pore Size Surface Area Analyzer after the sample was outgassed under vacuum at $473 \mathrm{~K}$.

Scanning electron microscopy (SEM) investigations have been carried out on a Tescan Vega II SBH microscope at an acceleration voltage of $30 \mathrm{kV}$. Before analysis, all samples sputter-coated with a thin layer of gold (30nm) (using a EMS 550X Sputter Coater). As well, transmission electron microscopy (TEM) investigations have been carried out on a Hitachi High-Tech HT7700 HT7700, designed with groundbreaking features, chief among these is that superior level of operability and the extensive range of useful digital imaging functions.

FTIR spectra were recorded with a Bruker Vertex FTIR spectrometer, resolution $2 \mathrm{~cm}^{-1}$, in the range of $4000-400 \mathrm{~cm}^{-1}$ by $\mathrm{KBr}$ pellet technique. The FTIR experiments were performed both for unloaded and loaded ordered mesoporous carbon materials.

The concentration change of methyl orange was determined by the Shimadzu 2401 UV-Vis spectrophotometer, on a pre-registered calibration curve of standard methyl orange solutions.

\section{Ordered mesoporous carbon synthesis}

The mesoporous carbon samples were prepared by a simple nanocasting route, using the mesoporous ordered silica SBA-15 as template and glycerol as carbon source. The silica template, SBA-15, was synthesized using a tri-block copolymer (Pluronic P123) by a sol-gel method [8]. In a typical synthesis of ordered mesoporous carbon [4], the SBA-15 silica was loaded with a $10 \%$ glycerol solution by dry impregnation method. The resulted mixture was then subjected to polymerization and the formed polymer-silica composite was pyrolyzed in a tubular oven at a temperature of $1073 \mathrm{~K}$, under nitrogen flow. Afterward, the SBA-15 silica framework was removed in order to separate the carbon structure [4].

$\mathrm{TiO}_{2}$ and $\mathrm{Bi}_{2} \mathrm{O}_{3}$ /ordered mesoporous carbon nanoarchitectures synthesis

The experimental procedure of supporting semiconducting 
oxide nanoparticles is based on the dry-impregnation technique, which consist of drying first the synthesized mesoporous carbon material at $473 \mathrm{~K}$ for $2 \mathrm{~h}$. Afterward, the hot sample has been contacted with $5 \%$ titanium (IV) butoxide alcoholic solution, with the impregnation ratio of 1:10. Thus, the carbon sample adsorbs quick the titania precursor molecules leading them to the internal mesopores. The same procedure was followed for the impregnation of bismuth oxide precursor solution. Therefore, $\mathrm{Bi}\left(\mathrm{NO}_{3}\right)_{3} \cdot 5 \mathrm{H}_{2} \mathrm{O}$ was dissolved in 1.12 $\mathrm{M} \mathrm{HNO}_{3}$ solution to avoid the hydrolysis, and the resulted solution was adsorbed by the hot carbon sample. The titanium (IV) butoxide/carbon sample was then suspended in 50ml of isopropyl alcohol, where the hydrolysis was carried out with $5 \mathrm{ml}$ of distilled water, slowly dropped during sonication. Likewise, the ultrasound-assisted hydrolysis of $\mathrm{Bi}\left(\mathrm{NO}_{3}\right)_{3}$ over the carbon was performed by dripping $50 \mathrm{ml}$ of $0.2 \mathrm{M} \mathrm{NaOH}$ aqueous solution. Both mixtures were irradiated with highintensity ultrasound at room temperature, in ambient air, for $75 \mathrm{~min}$. During ultrasound irradiation process, the temperature of the reaction mixtures raised up to $333 \mathrm{~K}$. After that, the mixtures were filtered and washed several times with distilled water and ethanol, and the resulted solids were dried at room temperature overnight. Finally, the oxide semiconductor/ carbon composites have been obtained by annealing at $673 \mathrm{~K}$, in $\mathrm{N}_{2}$ flow (with a heating rate of $5^{\circ} \mathrm{C} / \mathrm{min}$ ). The obtained samples were labeled as $\mathrm{C}-\mathrm{TiO}_{2}$ and $\mathrm{C}-\mathrm{Bi}_{2} \mathrm{O}_{3}$.

\section{Photocatalytic tests}

The photocatalytic experiments have employed the investigation of the UV-assisted degradation reaction of methyl orange, from aqueous media, at room temperature using a $6 \mathrm{~W}$ Vilber Lourmat UV-lamp ( $\lambda=365 \mathrm{~nm})$. The solid/liquid ratio was maintained constant during all experiments. After 30minutes dark run, where the adsorption-desorption equilibrium was achieved, the photocatalytic rection was initiated by switching on the UV light. Moreover, in order to avoid the influence of the outer light, all photocatalytic tests have been carried out in a closet where only the UV-lamp illuminated. Thus, only photons emitted by the UV-source was responsible for the dye bleaching process. The start concentration of MO solution $\left(C_{0}\right)$ was $40 \mathrm{mg} / \mathrm{L}$ and the experimental $\mathrm{pH}$ of 5.4 for both $\mathrm{C}-\mathrm{TiO}_{2}$ and $\mathrm{C}-\mathrm{Bi}_{2} \mathrm{O}_{3}$ samples.

The bleaching of MO solution was monitored by measuring the $\mathrm{MO}$ concentration at established time intervals, by checking the absorbance at characteristic wavelengths of $272 \mathrm{~nm}$ and $465.5 \mathrm{~nm}$, on the UV-Vis spectrophotometer.

\section{Results and discussions}

\section{Structural characterization}

The ordering of the porous carbon structure was confirmed by small-angle X-ray powder diffraction. Thus, the smallangle XRD pattern of the carbon material shows that it has a hexagonally ordered mesoporous structure, as evident from the presence of diffraction peaks indexed as (100) and (110) reflections of the two-dimensional hexagonal space group p6mm [4].
When $\mathrm{TiO}_{2}$ and $\mathrm{Bi}_{2} \mathrm{O}_{3}$ nanopartciles have been supported on the carbon structure (Figure 1), the widening of (100) diffraction peak was observed, as well as diminished intensity, while the (110) reflection disappeared, as can be observed in Figures 1a,b inset. Accordingly, it can be argued that the decrease of the pore ordering in the carbon structure occurs after $\mathrm{TiO}_{2}$ and $\mathrm{Bi}_{2} \mathrm{O}_{3}$ nanoparticles deposition during annealing process.

The wide-angle $\mathrm{X}$-ray diffraction patterns proved the formation of oxide semiconductor crystalline phases in prepared composite samples. Thus, the wide-angle XRD patterns (Figure 2) recorded on $\mathrm{C}-\mathrm{TiO}_{2}$ and $\mathrm{C}-\mathrm{Bi}_{2} \mathrm{O}_{3}$ samples clearly indicate the successful formation of oxide semiconductors crystalline phase inside ordered mesoporous carbon structure. As result, in the $\mathrm{C}-\mathrm{TiO}_{2}$ composite sample evidenced that the anatase was the only formed titania crystalline phase [9]. This was confirmed by the appearance of the diffraction peak emerging at $2 \theta \sim 25.29^{\circ}$, indexed as (101) reflection, which is characteristic to anatase phase of tetragonal symmetry belonging to $\mathrm{P} 42 / \mathrm{mnm}(136)$ space group (JCPDS card no. 88-1175). This result is of great importance for the photocatalytic processes, as anatase exhibits the highest photocatalytic activity among the other titania crystalline phases. Thus, no rutile or brookite phases were detected in the $\mathrm{C}-\mathrm{TiO}_{2}$ composite sample. On the other hand, the diffraction pattern of $\mathrm{C}-\mathrm{Bi}_{2} \mathrm{O}_{3}$ composite sample showed that the major crystal phase of $\alpha-\mathrm{Bi}_{2} \mathrm{O}_{3}$ is formed (according to JCPDS card no. 71-2274) [10], with a monoclinic symmetry belonging to the $P_{21 / c}(14)$ space group. The Scherrer equation allowed to calculate the average of crystallite sizes. Thus, the
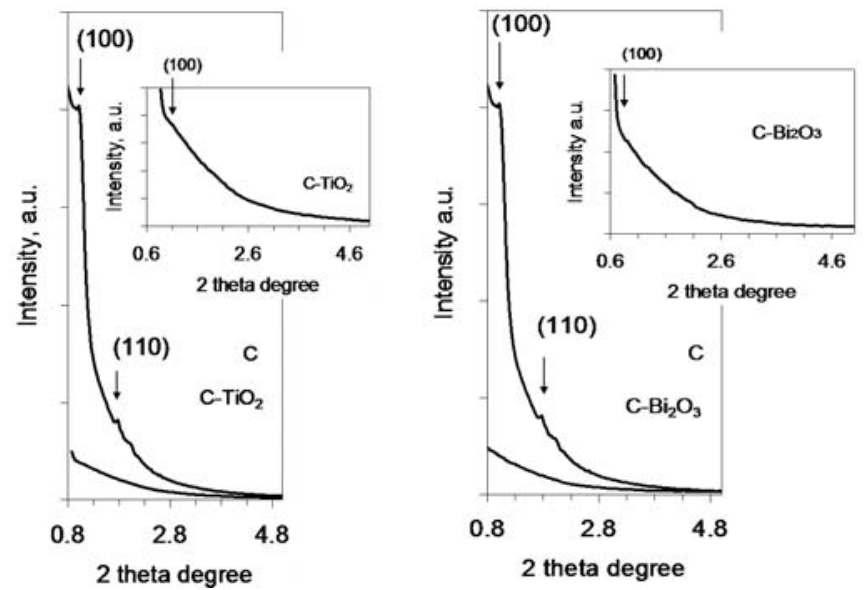

Figure 1: The low angle XRD patterns of the unloaded $(\mathrm{C})$ and $\mathrm{TiO}_{2}$ or $\mathrm{Bi}_{2} \mathrm{O}_{3}$ loaded ordered mesoporous carbon material ( $\mathrm{C}-\mathrm{TiO}_{2}$ and $\mathrm{C}-\mathrm{Bi}_{2} \mathrm{O}_{3}$, respectively)
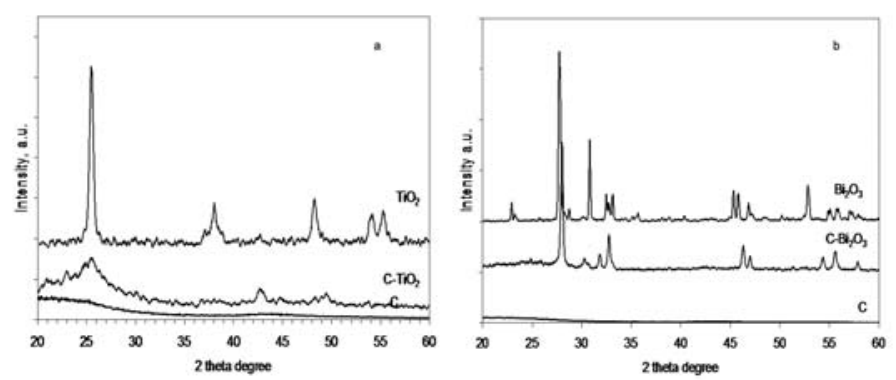

Figure 2: The wide angle $\mathrm{X}$-ray diffraction patterns of the unloaded and $\mathrm{TiO}_{2}$ respectively $\mathrm{Bi}_{2} \mathrm{O}_{3}$, loaded ordered mesoporous carbon material. 
sizes of unsupported and supported $\alpha-\mathrm{Bi}_{2} \mathrm{O}_{3}$ crystallites are of appropriate values, of $30.79 \mathrm{~nm}$ and $31.15 \mathrm{~nm}$, respectively. The small difference may be explained in terms of the formation of $\alpha-\mathrm{Bi}_{2} \mathrm{O}_{3}$ nanoparticles during the ultrasound treatment. Returning to $\mathrm{C}-\mathrm{TiO}_{2}$ pattern, the evaluation of the crystallite size of $\mathrm{TiO}_{2}$ was difficult, as the (101) diffraction peak of anatase overlapped the (002) reflection of ordered mesoporous carbon support. Therefore, another technique for crystallite size evaluation should be considered.

Further, SAXS profiles come to provide more information about the sizes and shapes of the prepared nanostructures. Thus, one dimensional (1D) SAXS profiles (Figure 3) appear linearly decrease with increasing of $s$ value in logarithm scale, suggesting the formation of long rod-like shaped nanostructures. Furthermore, the shape of the $P(R)$ function curves (Figure 3) exhibit the typical features of elongated cylindrical structures, as anticipated from the 1D SAXS profiles [13].

\section{Textural and morphological investigation}

In order to determine the specific surface area of the unloaded and oxide semiconductors loaded carbon materials, the nitrogen adsorption-desorption isotherms were recorded (Figure 4). According to IUPAC classification, all isotherms exhibit a type IV with a $\mathrm{H} 1$ type hysteresis loop, reflecting the presence of a mesoporous structure of all samples [4]. Because the isotherm shape after nanoparticles supporting on the carbon framework has not been modified, indicating that the oxide semiconductor nanoparticles were deposited on the external surface of the carbon structure. The registered isotherms allowed to calculate BET specific surface area as $1392 \mathrm{~m}^{2} / \mathrm{g}$ for ordered mesoporous carbon support, and a little bit reduced values of $1196 \mathrm{~m}^{2} / \mathrm{g}$ and $1020 \mathrm{~m}^{2} / \mathrm{g}$, for C-TiO $\mathrm{C}_{2}$ and $\mathrm{C}-\mathrm{Bi}_{2} \mathrm{O}_{3}$, respectively. Since by loading oxide semiconductor nanoparticles the BET specific surface area and the total pore volume (Table 1) a slightly decrease is observed, it is an indication that a very small part of oxide semiconductor nanoparticles entered the mesopores of carbon material, while the major part of nanoparticles are located outside of mesopores. As the decrease of specific surface area is not so drastic, the assumption of un-altering of ordered mesoporous carbon structure is confirmed. With respect to $\mathrm{TiO}_{2}$ and $\alpha-\mathrm{Bi}_{2} \mathrm{O}_{3}$ synthesized nanoparticles, the $\mathrm{C}-\mathrm{TiO}_{2}$ and $\mathrm{C}-\mathrm{Bi}_{2} \mathrm{O}_{3}$ composite samples are characterized by enhanced textural properties given by the carbon support material. The corresponding pore size distributions were estimated using the Barrett-JoynerHalenda (BJH) method, applied on desorption branch of the isotherm (Figures $3 b, 4 b$ ), allowing to find out the mean pore size of $3.9 \mathrm{~nm}$.

The scanning electron micrographs of the unloaded (C) and $\mathrm{TiO}_{2}$ and $\mathrm{Bi}_{2} \mathrm{O}_{3}$ loaded ordered mesoporous carbon materials $\left(\mathrm{C}-\mathrm{TiO}_{2}\right.$ and $\mathrm{C}-\mathrm{Bi}_{2} \mathrm{O}_{3}$, respectively) are presented in Figure 5 (first line). The SEM image of the mesoporous carbon material shows that the long fiber/rod-like morphology from the parent silica template has been retained. With respect to $\mathrm{C}$ sample, some small parts/agglomerations were observed (SEM images of $\mathrm{TiO}_{2}$ and $\mathrm{Bi}_{2} \mathrm{O}_{3}$ loaded ordered mesoporous carbon).
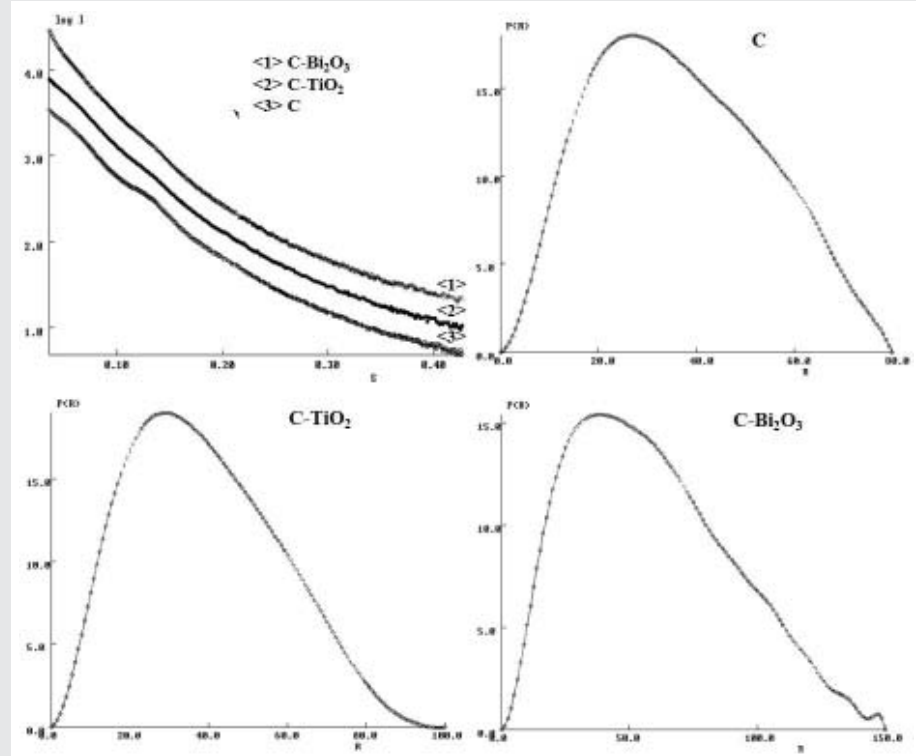

Figure 3: Small angle X-ray scattering intensities of C, C- $-\mathrm{TiO}_{2}$ and $\mathrm{C}-\mathrm{Bi}_{2} \mathrm{O}_{3}$ samples against the magnitude of wave vector, $\mathrm{S}$, plotted on logarithmic axes, and the pairdistance distribution functions (PDDF), $P(r)$, calculated from 1D SAXS profiles, of $C$, $\mathrm{C}-\mathrm{TiO}_{2}$ and $\mathrm{C}-\mathrm{Bi}_{2} \mathrm{O}_{3}$ samples.
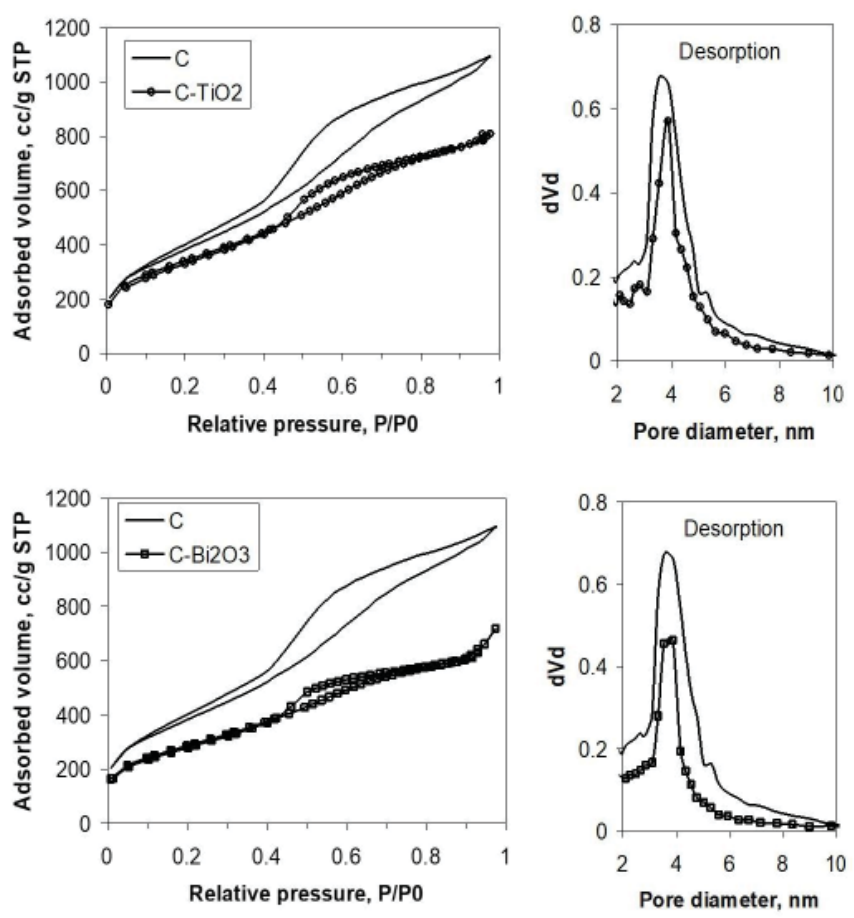

Figure 4: $\mathrm{N}_{2}$ sorption isotherm of ordered mesoporous carbon (C) and $\mathrm{TiO}_{2}-$ supported ordered mesoporous carbon $\left(\mathrm{C}-\mathrm{TiO}_{2}\right)$ samples and corresponding pore size distributions (first line), and of $\mathrm{Bi}_{2} \mathrm{O}_{3}$-supported ordered mesoporous carbon $\left(\mathrm{C}-\mathrm{Bi}_{2} \mathrm{O}_{3}\right)$ sample and corresponding pore size distributions (second line), respectively.

Table 1: Textural and structural properties of the synthesized materials.

\begin{tabular}{c|c|c|c|c|c|}
\hline Sample & $\mathbf{S}_{\mathrm{BET}}, \mathbf{m}^{2} / \mathbf{g}$ & $\mathbf{V P}, \mathbf{c c} / \mathbf{g}$ & Average pore diameter, $\mathbf{n m}$ & $\mathbf{d}, \mathbf{n m}$ & $\mathbf{a}_{\mathbf{0}}, \mathbf{n m}$ \\
\hline $\mathrm{C}$ & 1392 & 1.65 & 4.75 & 8.66 & 10.0 \\
\hline $\mathrm{C}-\mathrm{TiO}_{2}$ & 1196 & 1.23 & 4.10 & 0.35 & 0.40 \\
\hline $\mathrm{C}_{-}-\mathrm{Bi}_{2} \mathrm{O}_{3}$ & 1020 & 0.96 & 3.76 & 0.32 & 0.37 \\
\hline
\end{tabular}

$\mathrm{S}_{\mathrm{BET}}$ - specific surface area calculated from the linear part of the corresponding BET plot; VP - total pore volume taken at $0.95 \mathrm{P} / \mathrm{P}_{0}$; Average pore diameter was estimated by the BJH method; $d$ - the $d$-spacing of (100) reflection; $a_{0}$ - unit cell parameter calculated by the formula $a_{0}=\left(2 d_{100}\right) / \sqrt{ } 3$. 
These derive from the $\mathrm{TiO}_{2}$ and $\mathrm{Bi}_{2} \mathrm{O}_{3}$ nanoparticles deposition on the external surface of ordered mesoporous carbon. It is interesting to find that the mesoporous carbon material keeps its morphology, although bismuth oxide nanoparticles agglomerate more carbon nanorods than titanium oxide. The pore ordering in the carbon support material is also proved by TEM (Figure 5, second line), as well as the fiber/rod-like morphology. Because the XRD results could not provide the size of $\mathrm{TiO}_{2}$ nanoparticles, is was possible to measure it on TEM image, using an Image s software. Thus, were found $\mathrm{TiO}$ nanoparticles of $10 \mathrm{~nm}$, confirming that they widens the XRD peak, being undetectable nanoparticles by XRD. At the same time, TEM image of $\mathrm{Bi}_{2} \mathrm{O}_{3}$ nanoparticles deposited on carbon support confirm the diameter of $30 \mathrm{~nm}$ (as was calculated from $\mathrm{XRD)}$.

\section{Infrared spectroscopy analysis}

The chemical and structural properties of nanosized oxide semiconductors loaded ordered mesoporous carbon were analyzed with Fourier Transform Infrared spectroscopy (FTIR). The FTIR spectrum (transmission mode) of ordered mesoporous carbon (C), exhibit absorption bands of characteristic functional groups on its surface (Figure 6). However, the high absorbance of the carbon material required a very low sample concentration and therefore there was likely to be significant water contamination. It is accepted that the interpretation of surface groups to be qualitative, as they cannot be expected to behave as isolated functional groups. Thus, the absorption
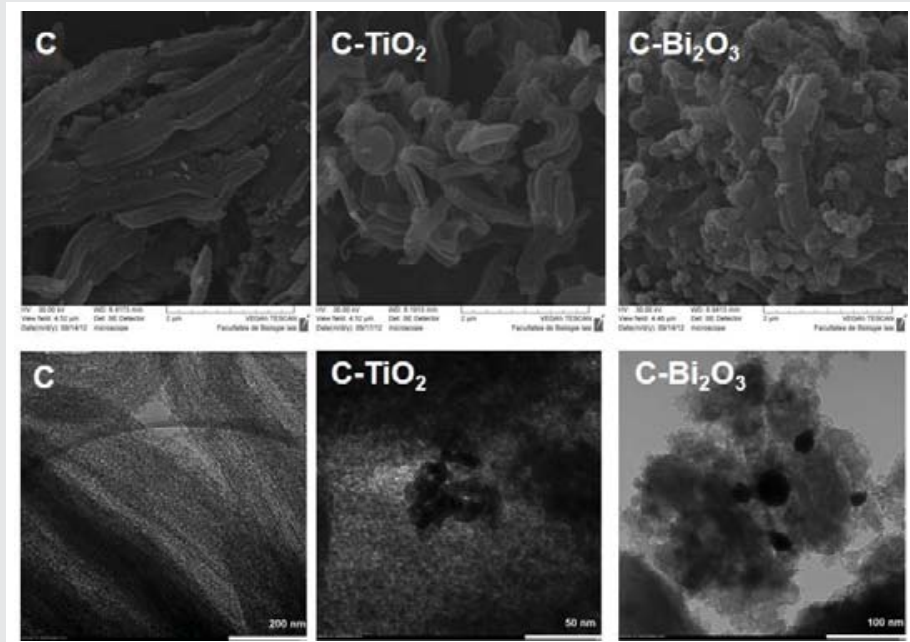

Figure 5: The SEM (first line) and TEM (second line) images of the $\mathrm{C}, \mathrm{C}_{-}-\mathrm{TiO}_{2}$ and $\mathrm{C}-\mathrm{Bi}_{2} \mathrm{O}_{3}$ samples.

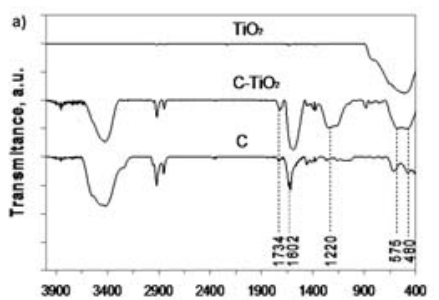

$39003400 \quad 2000 \quad 2400 \quad 1900$
Wavenumber, $\mathrm{cm}-1$

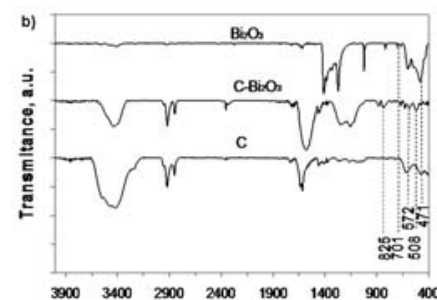

Wavenumber, $\mathrm{cm} \cdot 1$ band at $1602 \mathrm{~cm}^{-1}$ is assigned to the skeletal vibration of carbon structure. This peak is also observed in both spectra of $\mathrm{C}-\mathrm{TiO}_{2}$ and $\mathrm{C}-\mathrm{Bi}_{2} \mathrm{O}_{3}$ samples. The presence of $\mathrm{C}=\mathrm{O}$ functional groups is emphasized by the band at $1734 \mathrm{~cm}^{-1}$ and $-\mathrm{OH}$ functional groups appear as a broad band centered at $3500 \mathrm{~cm}^{-1}$, playing an important role in wetting process. Also, absorption bands of $\mathrm{O}-\mathrm{H}$ bending of carboxyl groups appear at $1450 \mathrm{~cm}^{-1}$. The presence of sharp transmission bands at $575 \mathrm{~cm}^{-1}$ and $480 \mathrm{~cm}^{-1}$ prove the presence of the crystallized $\mathrm{TiO}_{2}$ phase [11] (Figure $6 a)$. The absorption band in the range of $500-700 \mathrm{~cm}^{-1}$ is attributed to the $\mathrm{Ti}-\mathrm{O}-\mathrm{Ti}$ vibration of anatase [12], confirming XRD results. The broad band at $1220 \mathrm{~cm}^{-1}$ indicated that most likely Ti-O-C absorption band [13], is present in the spectrum of $\mathrm{C}-\mathrm{TiO}_{2}$ sample (Figure $6 \mathrm{a}$ ), proving that titanium dioxide is bonded to the carbon surface, where the synergistic effect has its origin.

Further, the FTIR spectrum of $\mathrm{C}-\mathrm{Bi}_{2} \mathrm{O}_{3}$ samples (Figure 6b) reveal the characteristic absorption band at $825 \mathrm{~cm}^{-1}$ attributed to $\mathrm{Bi}-\mathrm{O}-\mathrm{Bi}$ bond, and the strong absorption band recorded at $471 \mathrm{~cm}^{-1}$ is due to the stretching mode of $\mathrm{Bi}-\mathrm{O}$ bonds in $\mathrm{BiO}_{6}$ octahedral units $[15,16]$. As well, the observed absorption band at $701 \mathrm{~cm}^{-1}$ has been assigned to symmetric stretching vibrations of $\mathrm{Bi}-\mathrm{O}$ bonds in $\mathrm{BiO}_{3}$ pyramidal units. These results are in good agreement with the data reported by Carrazan, et al., [17] and Fruth, et al., [18], where is suggested that the absorption in the range of $600-400 \mathrm{~cm}^{-1}$ and $800-400 \mathrm{~cm}^{-1}$, respectively, is correlated with the stretching mode vibration of $\mathrm{Bi}-\mathrm{O}$. The absorption bands at 508 and $572 \mathrm{~cm}^{-1}$ in FTIR spectra are signed to $\alpha-\mathrm{Bi}_{2} \mathrm{O}_{3}[18,19]$, the results being in good agreement with XRD data discussed above.

All data confirm that the ultrasound assisted synthesis is the right way to produce nanosized oxide semiconductors/ ordered mesoporous carbon architectures composites.

\section{Photocatalytic activity}

Further, the functional properties of $\mathrm{C}-\mathrm{TiO}_{2}$ and $\mathrm{C}-\mathrm{Bi}_{2} \mathrm{O}_{3}$ composite samples in terms of photocatalysis, referring to the reference materials $\mathrm{C}, \mathrm{TiO}_{2}$ and $\mathrm{Bi}_{2} \mathrm{O}_{3}$, have been investigated. Due to the high specific surface areas, the interfaces of $\mathrm{C}-\mathrm{TiO}_{2}$ and $\mathrm{C}-\mathrm{Bi}_{2} \mathrm{O}_{3}$ composite samples are expected to trap easily and quickly the photogenerated electron, or the photogenerated electron to diffuse to the ordered mesoporous carbon graphene sheets. Therefore, the bleaching of MO under UV light occurs as a result of appeared synergistic effect. When the adsorption equilibrium in dark (the first 30minutes) was achieved, a decrease of MO concentration have been observed, as well as the solution bleaching. Since MO bleaching under UV irradiation without photocatalysts was only about $2 \%$, this was considered a negligible value with respect to the MO bleaching in the presence of the synthesized composite photocatalysts. As observed, MO removal comes predominantly from photocatalytic degradation by oxide semiconductor nanoparticles supported on ordered mesoporous carbon. Thus, $\mathrm{C}-\mathrm{TiO}_{2}$ and $\mathrm{C}-\mathrm{Bi}_{2} \mathrm{O}_{3}$ photocatalysts led to a decrease of the $\mathrm{MO}$ concentration faster than the pure $\mathrm{TiO}_{2}$ and $\alpha-\mathrm{Bi}_{2} \mathrm{O}_{3}$ powders, respectively. These results indicate that the ordered mesoporous carbon enhances the photocatalytic activity of 
semiconductor oxide nanoparticles, that is attributable to the high specific surface area of carbon support, as well as due to the fact that the carbon support acts as an electron reservoir and possesses great electron transfer properties [20]. Also, high photocatalytic activity of the obtained architectures is due to the graphitic carbon structure that is able to promote a rapid photoinduced charge separation and slow charge recombination, by accepting the photogenerated electrons from photocatalytic nanoparticles. Thus, the carbon support works as an effective adsorbent to concentrate $\mathrm{MO}$ around the photocatalytic nanoparticles, providing high MO concentration for photocatalytic reaction (Figure 7).

The photocatalytic bleaching experiments allowed to evaluate the efficiencies of nanosized oxide semiconductors/ ordered mesoporous carbon architectures, that are observed to be improved compare to that of the pure oxides. After 3 hour of UV irradiation the efficiencies of oxide semiconductors/ ordered mesoporous carbon nanoarchitectures achieved about $95-98 \%$ in MO bleaching process. Therefore, the synthesized composite materials could be an interesting alternative for anionic dye bleaching from waste waters.

\section{Conclusions}

By this work, we described a successful way for the synthesis of nanosized oxide semiconductors/ordered mesoporous carbon nanoarchitectures using ultrasounds. It was observed that the carbon structure was not altered in any way. Even more, the mesoporous carbon played an important role in promoting a rapid photoinduced charge separation and slowing down the charge recombination. As well, the ordered mesoporous carbon nanostructure contributes to the increase of the specific surface area of nanosized oxide semiconductor nanoparticles, thus increasing the surface contact with the dye molecules to be bleached from solutions. Therefore, a high specific surface area of the synthesized composites was determined to be much larger than that of un-supported nanoparticles. By supporting on the carbon framework, was proved that the nanoparticle agglomeration can be avoided.

The synthesis is considered to be a successful one in terms of crystallinity of the synthesized samples. The crystalline phases of $\mathrm{C}-\mathrm{TiO}_{2}$ and $\mathrm{C}-\mathrm{Bi}_{2} \mathrm{O}_{3}$ composite samples were proved to be high photoactive, as a result of the synergistic effect arising from the combination of semiconductor metal oxide nanoparticles and mesoporous carbon structure.

\section{Acknowledgement}

This work was supported by a grant of Ministry of
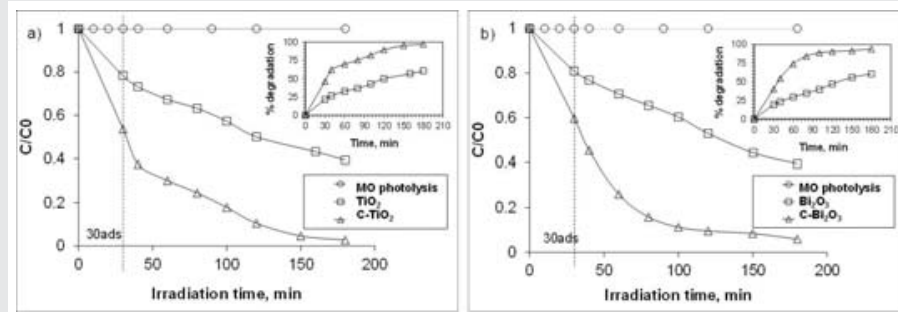

Figure 7: Photocatalytic degradation behavior of $\mathrm{MO}$ for the $\mathrm{C}-\mathrm{TiO}_{2}$ and $\mathrm{C}-\mathrm{Bi}_{2} \mathrm{O}$ samples compared with $\mathrm{TiO}_{2}$ and $\mathrm{Bi}_{2} \mathrm{O}_{3}$ nanoparticles prepared in this work
Research and Innovation, CNCS - UEFISCDI, project number PN-III-P1-1.1-TE-2016-0805, within PNCDI III and POSDRU/89/1.5/S/63663.

\section{References}

1. Bang JH, Suslick KS (2010) Applications of Ultrasound to the Synthesis of Nanostructured Materials. Adv Mater 22: 1039-1059. Link: http://bit.ly/2tobwOx

2. Bohme K, Einicke WD, Klepel O (2005) Templated synthesis of mesoporous carbon from sucrose - the way from the silica pore filling to the carbon material. Carbon 43: 1918-1925. Link: http://bit.ly/2UjL6sf

3. Li Y, Zhang S, Yu Q, Yin W (2007) The effects of activated carbon supports on the structure and properties of $\mathrm{TiO}_{2}$ nanoparticles prepared by a sol-gel method. Appl Surf Sci 253: 9254-9258. Link: http://bit.ly/20nsvaQ

4. Ignat M, Van Oers CJ, Vernimmen M, Mertens S, Potgieter-Vermaak V, et al. (2010) Textural property tuning of ordered mesoporous carbon obtained by glycerol conversion using SBA-15 silica as template. Carbon 48: 1609-1618. Link: http://bit.ly/2SfFGM3

5. Ignat $\mathrm{M}$, Coromelci $\mathrm{C}$, Popovici E (2012) $\mathrm{TiO}_{2}$-coated Ordered Mesoporous Carbon for Phenol Photodegradation. Rev Chim (Bucharest) 63: 358-361. Link: http://bit.ly/2SbsN5T

6. Oliveira A, Saggioro E, Barbosa N, Mazzei A, Ferreira LF, et al. (2011) Surface Photocatalysis: A study of the thickness of $\mathrm{TiO}_{2}$ layers on the photocatalytic decomposition of soluble indigo blue dye. Rev Chim (Bucharest) 62: 462-468. Link: http://bit.ly/3ba5tye

7. He WD, Qin $W, W u X H$, Ding XB, Chen L, et al. (2007) The photocatalytic properties of bismuth oxide films prepared through the sol-gel method. Thin Solid Films 515: 5362-5365. Link: http://bit.ly/2Sgs1EL

8. Hartmann M, Vinu A (2002) Mechanical stability and porosity analysis of large-pore SBA-15 mesoporous molecular sieves by mercury porosimetry and organics adsorption. Langmuir 18: 8010-8016. Link: http://bit.ly/393DNcq

9. Thamaphat K, Limsuwan P, Ngotawornchai B (2008) Phase characterization of $\mathrm{TiO}_{2}$ powder by XRD and TEM. Kasetsart $\mathrm{J}$ (Nat Sci) 42: 357-361. Link: http://bit.ly/2tmxX6A

10. Periasamy AP, Yang S, Chen SM (2011) Preparation and characterization of bismuth oxide nanoparticles-multiwalled carbon nanotube composite for the development of horseradish peroxidase based $\mathrm{H}_{2} \mathrm{O}_{2}$ biosensor. Talanta 87: 15 23. Link: http://bit.ly/393GGKk

11. Katsumata K, Matsushita N, Okada K (2012) Preparation of $\mathrm{TiO}_{2}$-Fullerene Composites and Their Photocatalytic Activity under Visible Light. Int $\mathrm{J}$ Photoenerg 9. Link: http://bit.ly/2ScTgjt

12. Hu G, Meng X, Feng X, Ding Y, Zhang S, et al. (2007) Anatase $\mathrm{TiO}_{2}$ nanoparticles/ carbon nanotubes nanofibers: preparation, characterization and photocatalytic properties. J Mat Sci 42: 7162-7170. Link: http://bit.ly/393x3v3

13. Svergun DI, Koch MHJ (2003) Small-angle scattering studies of biological macromolecules in solution. Rep Prog Phys 66: 1735-1782. Link: http://bit.ly/2vNserz

14. Șener Ș, Erdemoglu M, Asiltirk M, Sayilkan H (2005) The effect of silane modification on the adsorptive properties of natural pyrophyllite and synthetic titanium-based powders prepared by the sol-gel process. Turk J Chem 29 : 487-495. Link: http://bit.ly/2RPGgkT

15. Doweidar H, Saddeek YB (2009) FTIR and ultrasonic investigations on modified bismuth borate glasses. J Non-Cryst Solids 355: 348-354. Link: http://bit.ly/31uYSKI

16. Ardelean I, Cora S, Rusu D (2008) EPR and FT-IR spectroscopic studies of $\mathrm{Bi}_{2} \mathrm{O}_{3}-\mathrm{B}_{2} \mathrm{O}_{3}-\mathrm{CuO}$ glasses. Physica B Condensed Matter 403: 3682-3685. Link: http://bit.ly/20kMln2 
17. Carrazan SRG, Martin C, Rives V, Vidal R (1996) An FT-IR spectroscopy study of the adsorption and oxidation of propene on multiphase $\mathrm{Bi}, \mathrm{Mo}$ and Co catalysts. Spectrochimica Acta Part A: Molecular and Biomolecular Spectroscopy 52: 1107-1118. Link: http://bit.ly/2RVxHVP

18. Fruth V, Popa M, Berger D, lonica CM, Jitianu M (2004) Phases investigation in the antimony doped $\mathrm{Bi}_{2} \mathrm{O}_{3}$ system. J Eur Ceram Soc 24: 1295-1299. Link: http://bit.ly/31j4yH7
19. Gondal MA, Saleh TA, Drmosh Q (2012) Optical properties of bismuth oxide nanoparticles synthesized by pulsed laser ablation in liquids. Science of Advanced Materials 4: 507-510. Link: http://bit.ly/2UlthJs

20. Zhang L, Ghimire P, Phuriragpitikhon J, Jiang B, Gonçalves AAS, et al. (2018) facile formation of metallic bismuth/bismuth oxide heterojunction on porous carbon with enhanced photocatalytic activity. J Colloid Interface Sci 513: 8291. Link: http://bit.ly/20mNtqC

Discover a bigger Impact and Visibility of your article publication with Peertechz Publications

\section{Highlights}

- Signatory publisher of ORCID

- Signatory Publisher of DORA (San Francisco Declaration on Research Assessment)

* Articles archived in worlds' renowned service providers such as Portico, CNKI, AGRIS, TDNet, Base (Bielefeld University Library), CrossRef, Scilit, J-Gate etc.

* Journals indexed in ICMJE, SHERPA/ROMEO, Google Scholar etc.

* OAI-PMH (Open Archives Initiative Protocol for Metadata Harvesting)

* Dedicated Editorial Board for every journal

* Accurate and rapid peer-review process

* Increased citations of published articles through promotions

* Reduced timeline for article publication

Submit your articles and experience a new surge in publication services (https://www.peertechz.com/submission).

Peertechz journals wishes everlasting success in your every endeavours.

Copyright: (C) 2020 Ignat M, et al. This is an open-access article distributed under the terms of the Creative Commons Attribution License, which permits unrestricted use, distribution, and reproduction in any medium, provided the original author and source are credited. 